\title{
Pediatric hydrocephalus: systematic literature review and evidence-based guidelines. Part 3: Endoscopic computer-assisted electromagnetic navigation and ultrasonography as technical adjuvants for shunt placement
}

\author{
Ann Marie Flannery, M.D., ${ }^{1}$ Ann-Christine Duhaime, M.D., ${ }^{2}$ \\ Mandeer S. Tamber, M.D., Ph.D., ${ }^{3}$ and Joanna Kemp, M.D. ${ }^{1}$ \\ ${ }^{I}$ Department of Neurological Surgery, Saint Louis University, St. Louis, Missouri, ${ }^{2}$ Department of Pediatric \\ Neurosurgery, Massachusetts General Hospital, Boston, Massachusetts; and ${ }^{3}$ Department of Pediatric \\ Neurological Surgery, Children's Hospital of Pittsburgh, University of Pittsburgh, Pittsburgh, Pennsylvania
}

\begin{abstract}
Object. This systematic review was undertaken to answer the following question: Do technical adjuvants such as ventricular endoscopic placement, computer-assisted electromagnetic guidance, or ultrasound guidance improve ventricular shunt function and survival?

Methods. The US National Library of Medicine PubMed/MEDLINE database and the Cochrane Database of Systematic Reviews were queried using MeSH headings and key words specifically chosen to identify published articles detailing the use of cerebrospinal fluid shunts for the treatment of pediatric hydrocephalus. Articles meeting specific criteria that had been delineated a priori were then examined, and data were abstracted and compiled in evidentiary tables. These data were then analyzed by the Pediatric Hydrocephalus Systematic Review and EvidenceBased Guidelines Task Force to consider evidence-based treatment recommendations.

Results. The search yielded 163 abstracts, which were screened for potential relevance to the application of technical adjuvants in shunt placement. Fourteen articles were selected for full-text review. One additional article was selected during a review of literature citations. Eight of these articles were included in the final recommendations concerning the use of endoscopy, ultrasonography, and electromagnetic image guidance during shunt placement, whereas the remaining articles were excluded due to poor evidence or lack of relevance.

The evidence included 1 Class I, 1 Class II, and 6 Class III papers. An evidentiary table of relevant articles was created.

Conclusions. Recommendation: There is insufficient evidence to recommend the use of endoscopic guidance for routine ventricular catheter placement. STRENGTH OF RECOMMENDATION: Level I, high degree of clinical certainty.

RECOMMENDATION: The routine use of ultrasound-assisted catheter placement is an option. STRENGTH OF RECOMMENDATION: Level III, unclear clinical certainty.

RECOMMENDATION: The routine use of computer-assisted electromagnetic (EM) navigation is an option. STRENGTH OF RECOMMENDATION: Level III, unclear clinical certainty.
\end{abstract}

(http://thejns.org/doi/abs/10.3171/2014.7.PEDS14323)

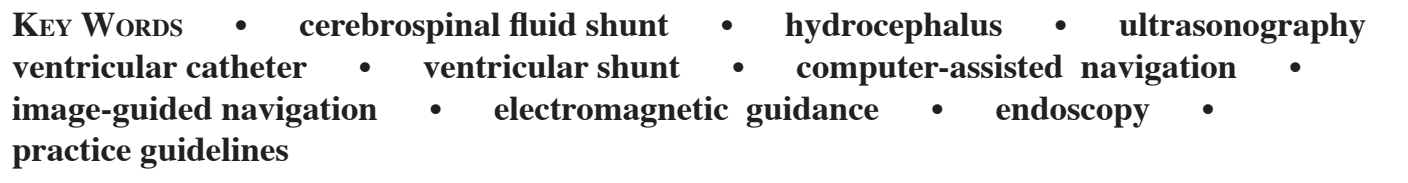

A S navigation, imaging, and endoscopy have increasingly been used in the field of neurosurgery, they have been applied to the placement of CSF shunts. Surgeons have used these technical adjuvants in attempts to accomplish good catheter placement with the hopes of improving the longevity of the shunt as well as

Abbreviations used in this paper: AANS $=$ American Association of Neurological Surgeons; CNS = Congress of Neurological Surgeons; EM = electromagnetic ; ETV = endoscopic third ventriculostomy. reducing potential complications. This specific systematic review was undertaken to answer the following question: Do technical adjuvants such as ventricular endoscopic placement, computer-assisted electromagnetic (EM) guidance, or ultrasound guidance improve ventricular shunt function and survival? As seen in the following Methods section, we conducted a search for articles on the use of CSF shunts in pediatric patients with hydrocephalus. The original search yielded 163 abstracts, which were screened for their potential relevance to the application of technical adjuvants in shunt placement. Fifteen arti- 
cles were deemed relevant. Eight of these articles were included in the final recommendations for the use of endoscopy, ultrasonography, or EM image guidance in the placement of shunts, with the remainder excluded due to poor evidence or lack of relevance.

\section{Methods}

The US National Library of Medicine PubMed/ MEDLINE database and the Cochrane Database of Systematic Reviews were queried for the period January 1966 through March 2012 using MeSH headings and key words specifically chosen to identify published articles detailing the use of CSF shunts for the treatment of pediatric hydrocephalus. Please see below for the specific search terms and strategies used (Fig. 1).

\section{Search Terms}

PubMed/MEDLINE

1. ("Cerebrospinal Fluid Shunts"[MeSH]) AND "Hydrocephalus"[MeSH:noexp]
2. Limit 1 to Child (0-18 years)

3. 2 and ((ventricular AND (catheter OR shunt)) AND ("computer assisted" OR "image guided" OR electromagnetic OR ultrasound OR Endoscopy[MeSH] OR endoscop*))

4. Limit to English and Humans

Cochrane Database

1. MeSH descriptor Child

2. MeSH descriptor Infant Shunts)

3. 1 or 2 and (MeSH descriptor Cerebrospinal Fluid

4. 3 and (MeSH descriptor Hydrocephalus)

5. 4 and (ventricular NEAR/2 (catheter OR shunt))

6. (computer OR ultrasound OR endoscop*)

7. 5 and 6

Search Strategies

Articles meeting specific criteria that had been delineated a priori were then examined, and the data yielded were abstracted and compiled in evidentiary tables (Ta-

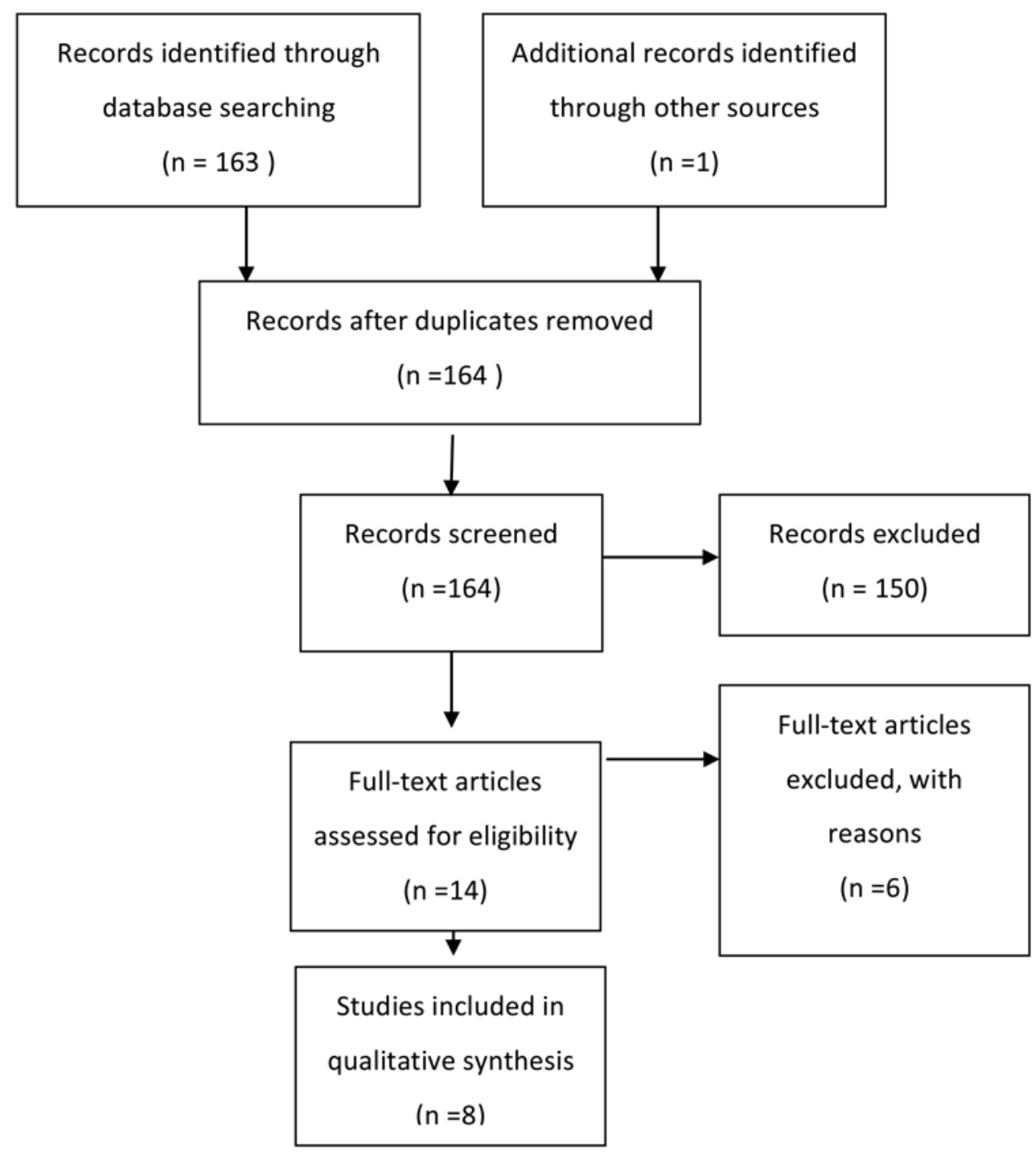

FIG. 1. Flowchart showing the process involved in identifying relevant literature. 
bles $1-3)$. These data were then analyzed by the Pediatric Hydrocephalus Systematic Review and Evidence-Based Guidelines Task Force to consider evidence-based treatment recommendations.

\section{Endoscopy}

\section{Results}

RECOMmEndation: There is insufficient evidence to recommend using endoscopic guidance for routine ventricular catheter placement. STRENGTH of ReCOMmEndATION: Level I, high degree of clinical certainty.

Four studies were identified to assess the use of endoscopy in the placement of ventricular catheters (Table 1). Two of the earlier reports in the literature described a case series by Vries ${ }^{14}$ and another by Kellnar et al. ${ }^{6}$ Vries $^{14}$ described the technique for insertion of endoscopically placed catheters and reported that $79 \%$ of patients for whom endoscopy was used did not require further shunt revision. However, the author did not report the follow-up period, and without a control arm there is no clear demonstration of an advantage of using the endoscope over the standard technique, which relies on anatomical landmarks. Kellnar et al. ${ }^{6}$ described a case series in which neuroendoscopy was used for placement of ventricular catheters in 14 patients. These authors demonstrated the feasibility of their technique and stated that there were no revisions due to catheter malposition during an 18-month followup period. ${ }^{6}$ Again, without a control group, no conclusions can be drawn regarding an advantage of endoscopic shunt insertion over standard techniques.

A later study by Villavicencio et al. ${ }^{13}$ retrospectively compared the survival of shunts placed with neuroendoscopic guidance to that of shunts placed without guidance. The authors found no advantage to overall shunt survival between the two study groups (hazard ratio $1.08,95 \% \mathrm{CI}$ 0.84-1.41). They did, however, note that the risk of proximal failure was lower in the endoscopy group (odds ratio $0.56,95 \%$ CI $0.32-0.93$ ) and observed an increased rate of distal malfunction when compared with shunts placed without endoscopic assistance.

The strongest evidence that the routine use of endoscopic placement did not improve outcome was reported by Kestle and colleagues ${ }^{7}$ in a randomized controlled trial in which 393 patients requiring a shunt were randomized into either an endoscopy group or a standard group. There were no significant differences in the overall shunt survival rate between the groups $(\mathrm{p}=0.09)$ or in the postoperative assessment of optimal catheter placement (away from the choroid plexus). The most common cause of shunt failure was proximal obstruction in both groups.

TABLE 1: Use of endoscopy in the placement of ventricular catheters: summary of evidence*

\begin{tabular}{|c|c|c|c|}
\hline Authors \& Year & Study Description & $\begin{array}{l}\text { Data Class, Quality, } \\
\text { \& Reason(s) }\end{array}$ & Results \& Conclusions \\
\hline $\begin{array}{l}\text { Kestle et al., } \\
2003\end{array}$ & $\begin{array}{l}\text { Endoscopic placement of new shunts at } \\
16 \text { centers, randomized to endoscope } \\
\text { directed vs non-endoscope directed. } \\
393 \text { pts in study, ventricular catheter scope. }\end{array}$ & $\begin{array}{l}\text { Class I } \\
\text { Randomized, blinded, } \\
\text { multicenter. }\end{array}$ & $\begin{array}{l}\text { Incidence of shunt failure at } 1 \text { yr: Endoscope Insertion } \\
\text { Group: } 42 \% \text {; Non-Endoscopic Insertion Group: } 34 \% \text {. } \\
\text { Time to 1st shunt failure did not differ between groups } \\
\text { (log-rank = 2.92, } p=0.09 \text { ). }\end{array}$ \\
\hline $\begin{array}{l}\text { Villavicencio et } \\
\text { al., } 2003\end{array}$ & $\begin{array}{l}447 \text { children underwent total of } 965 \text { shunt } \\
\text { placements or revisions. } \\
605 \text { catheters ( } 63 \%) \text { placed w/ aid of endo- } \\
\text { scope; } 360 \text { catheters }(37.3 \%) \text { placed w/o } \\
\text { endoscope. }\end{array}$ & $\begin{array}{l}\text { Class III } \\
\text { Retrospective review, } \\
\quad \text { historical cohort. }\end{array}$ & $\begin{array}{l}\text { Neuroendoscopy did not independently affect risk of sub- } \\
\text { sequent shunt failure (HR } 1.08,95 \% \mathrm{Cl} 0.84-1.41) \text {. } \\
\text { Endoscopic placement: } \\
\text { 1. Independently decreased odds of proximal ob- } \\
\text { struction (OR } 0.56,95 \% \mathrm{Cl} 0.32-0.93) \text {; } \\
\text { 2. Increased odds of distal malfunction (OR 1.52, } \\
\quad 95 \% \mathrm{Cl} 1.02-2.72) ; \\
\text { 3. Was not associated w/ infection (OR 1.42, 95\% CI } \\
\text { 0.78-2.61). } \\
\text { Authors state, "Endoscope assisted ventricular catheter } \\
\text { placement decreased the odds of proximal obstruc- } \\
\text { tion but failed to improve overall shunt survival in this } \\
\text { 6-year experience." }\end{array}$ \\
\hline Vries, 1980 & $\begin{array}{l}2.7-\mathrm{mm} 0^{\circ} \text { scope used to place ventricular } \\
\text { catheter. } \\
102 \text { shunts in } 85 \text { pts, } 67 \text { were new shunts. }\end{array}$ & $\begin{array}{l}\text { Class III } \\
\text { Case series, retro- } \\
\text { spective, chart } \\
\text { review. } \\
\text { No statistical analysis. }\end{array}$ & $\begin{array}{l}\text { Max follow-up } 18 \text { mos. } \\
24 \text { shunt malfunctions in } 18 \text { pts: } 9 \text { were ventricular cath- } \\
\text { eter malfunctions. } 6 \text { infections. } \\
\text { Author reported that } 79 \% \text { of the shunts were "trouble- } \\
\text { free." }\end{array}$ \\
\hline $\begin{array}{l}\text { Kellnar et al., } \\
1995\end{array}$ & $\begin{array}{l}\text { 2.7-mm } 30^{\circ} \text { scope used in } 17 \text { children w/ } \\
\text { hydrocephalus. } \\
\text { Majority of pts had undergone surgeries } \\
\text { to correct malpositioned ventricular } \\
\text { catheters. Catheter implanted w/ aid of } \\
\text { ventriculoscope in } 14 \text { cases. }\end{array}$ & $\begin{array}{l}\text { Class III } \\
\text { Retrospective review, } \\
\text { case series \& } \\
\text { technical note. }\end{array}$ & $\begin{array}{l}\text { Within } 18 \text { mos, revision due to malposition was not } \\
\text { necessary. }\end{array}$ \\
\hline
\end{tabular}

${ }^{*}$ pts $=$ patients. 
Part 3: Effect of technical adjuvants on shunt function

TABLE 2: Use of ultrasound guidance in the placement of ventricular catheters: summary of evidence

\begin{tabular}{cccc}
\hline Authors \& Year & Study Description & $\begin{array}{c}\text { Data Class, Quality, } \\
\text { \& Reason(s) }\end{array}$ & Results \& Conclusions \\
\hline $\begin{array}{l}\text { Whitehead et al., } \\
2007\end{array}$ & $\begin{array}{c}\text { Authors used transcranial sonography via a 2-cm bur hole } \\
\text { for CSF ventricular catheter insertion. } \\
10 \text { pts w/o open fontanelles \& normal-size to slitlike ven- } \\
\text { tricles, July-December 2006. }\end{array}$ & $\begin{array}{l}\text { Class III } \\
\text { Case series \& technical note. }\end{array}$ & $\begin{array}{l}10 \text { of } 10 \text { catheters in ventricles. } \\
\text { No follow-up. } \\
\text { No data on shunt survival. }\end{array}$ \\
\hline
\end{tabular}

\section{Ultrasound Guidance}

RECOMMENDATION: The routine use of ultrasound-assisted catheter placement is an option. STRENGTH OF ReCOMMENDATION: Level III, unclear clinical certainty.

The supporting evidence consisted of 1 Class III study with limited follow-up and no control or comparison (Table 2).

Few studies have sought to evaluate the utility of ultrasound in the placement of ventricular catheters. One Class III cohort study with a limited follow-up and no control or comparison met the inclusion criteria and was included as evidence to support this topic. Whitehead et al. ${ }^{15}$ described the technique of placing the ventricular catheter with ultrasound guidance in pediatric patients with closed fontanelles. The authors described the creation of a $2-\mathrm{cm}$ bur hole, followed by catheter placement and ultrasonography to confirm catheter location. There was no analysis of outcomes related to shunt longevity, but immediate postoperative imaging did confirm the expected placement of the catheter away from the choroid

TABLE 3: Use of electromagnetic image guidance in the placement of ventricular catheters: summary of evidence

\begin{tabular}{|c|c|c|c|}
\hline Authors \& Year & Study Description & $\begin{array}{l}\text { Data Class, Quality, } \\
\quad \& \text { Reason(s) }\end{array}$ & Results \& Conclusions \\
\hline $\begin{array}{l}\text { Hayhurst et al., } \\
2010\end{array}$ & $\begin{array}{l}3 \text { centers, new shunts, adult \& pediatric } \\
\text { pts followed up for } 1 \text { yr or to shunt } \\
\text { failure. } \\
\text { Graded by observer blinded to place- } \\
\text { ment method. } \\
\text { Pediatric pts: } 20 \text { w/o navigation, } 15 \mathrm{w} / \\
\text { EM image navigation. }\end{array}$ & $\begin{array}{l}\text { Class II } \\
\text { Cohort, good-quality } \\
\text { prospective study. } \\
\text { Follow-up for EM image } \\
\text { navigation group was } \\
\text { shorter ( } 6 \text { mos) than for } \\
\text { no navigation group. } \\
\text { Small study, }<50 \% \text { pedi- } \\
\text { atric pts. }\end{array}$ & $\begin{array}{l}\text { Pediatric standard group (no navigation): } 20 \text { pts }<18 \text { yrs } \\
\text { of age. } 6 \text { shunts failed ( } 30 \% \text { ); in } 4 \text { cases early failures } \\
\text { due to proximal obstruction. } \\
\text { EM image navigation group: } 15 \text { children, } 3 \text { shunts failed } \\
\text { ( } 20 \% \text { ). Failures due to infection in } 1 \text { pt \& valve block- } \\
\text { age in } 2 \text { pts. } \\
\text { No significant difference in overall shunt failure in the } \\
\text { pediatric group when EM image guidance was used } \\
\text { for shunt placement ( } p=0.39 \text {, Fisher exact test). }\end{array}$ \\
\hline Clark et al., 2008 & $\begin{array}{l}\text { Prospective data collected from pediatric } \\
\text { pts who underwent ventriculoperi- } \\
\text { toneal shunt surgery in which EM } \\
\text { frameless neuronavigation was used, } \\
\text { January 2006- November } 2007 .\end{array}$ & $\begin{array}{l}\text { Class III } \\
\text { Case series. }\end{array}$ & $\begin{array}{l}\text { All ventricles cannulated on } 1 \text { st pass w/o immediate } \\
\text { or early postprocedural complications. Symptoms } \\
\text { (mainly chronic headache) resolved in all but } 1 \mathrm{pt} \text {. } \\
\text { Proximal revision rate } 9 \% \text { ( } 2 \text { of } 23 \mathrm{pts} \text { ). } \\
\text { Follow-up period: median } 7 \text { mos, range } 1-17 \text { mos. } \\
\text { Distal catheter revision: } 1 \mathrm{pt} \text {. } \\
\text { Infection: } 1 \mathrm{pt} \text {. } \\
\text { Proximal failure rate } 9 \% \text {. According to authors this was } \\
\text { significantly lower than some failure rates in literature. } \\
\text { Infection rate } 5 \%, \text { comparable to rates cited in } \\
\text { literature. }\end{array}$ \\
\hline Levitt et al., 2012 & $\begin{array}{l}89 \text { pts, } 102 \text { shunt surgeries: } 58 \text { initial \& } \\
44 \text { revisions. Image guidance used in } \\
56 \text { surgeries; standard technique } \\
\text { used in } 46 \text { surgeries. }\end{array}$ & $\begin{array}{l}\text { Class III } \\
\text { Retrospective review. }\end{array}$ & $\begin{array}{l}22 \% \text { shunt failure rate w/ standard technique; } 25 \% \text { shunt } \\
\text { failure rate w/ EM image guidance (not significant, } p= \\
0.21 \text {, log-rank test). } \\
\text { Ventricle size significantly smaller in pts in EM image } \\
\text { guidance group }(p<0.02 \text { ) \& in the surgery revision } \\
\text { group ( } p<0.01 \text { ), Student t-test. Small ventricle size } \\
\text { did not affect shunt failure rate, even when authors } \\
\text { controlled for technique of insertion. } \\
\text { Image guidance significantly improved accuracy of cath- } \\
\text { eter placement }(p<0.01 \text { ). Shunt placement accuracy } \\
\text { had no significant effect on shunt failure. Significant } \\
\text { improvement in catheter position, even though pts in } \\
\text { EM image guidance group had smaller ventricles. }\end{array}$ \\
\hline
\end{tabular}


plexus..$^{15}$ Ultrasound-assisted catheter placement may be used to confirm placement of the proximal catheter within the cerebral ventricle.

\section{Electromagnetic Image Guidance}

RECOMMENDATION: The routine use of computerassisted electromagnetic (EM) navigation is an option. STRENGTH OF RECOMMENDATION: Level III, unclear clinical certainty.

One Class II study, which did not reach significance in the pediatric subset, and 1 Class III study, which reported a decrease in proximal failure compared with historical reports, were included as evidence to support this topic.

Electromagnetic image guidance has been used (and studied in the pediatric hydrocephalus literature) as a technical adjuvant for assisting placement of ventricular catheters. In a case series by Clark et al., ${ }^{2}$ published in 2008, prospectively collected data confirmed the feasibility of using EM image guidance, specifically in 23 patients with anatomy that was difficult to navigate, including those with small and slit ventricles or complex loculated hydrocephalus. These authors demonstrated a $9 \%$ proximal revision rate in the 7-month follow-up period, which they compared with a historical control group in which there was a $35 \%$ failure rate. The authors proposed a randomized controlled trial to strengthen this evidence, as their study did not have its own control, had a short follow-up period, and included a small number of patients.

An article by Hayhurst and coauthors ${ }^{5}$ described a nonrandomized prospective cohort study in which standard shunt placement was compared with EM imageguided shunt placement in both adult and pediatric patients. The end points of the study were failure rates as well as grading of the catheter position as follows: Grade 1 , catheter tip floating in CSF equidistant from the ventricle walls, away from the choroid plexus, and in a straight trajectory from the bur hole; Grade 2, catheter tip touching the ventricle wall or the choroid plexus; and Grade 3, part of the catheter tip within the parenchyma or failure to cannulate the ventricle completely. The pediatric cases were analyzed separately with regard to shunt failure, and the data showed a $30 \%$ failure rate in the standard cohort and a $20 \%$ failure rate in the EM image guidance cohort. This difference was statistically insignificant. In the entire cohort, which included both adult and pediatric patients, "the rate of proximal obstruction falls ... from 17 to $6 \%$ [when] using EM-navigated placement $(\mathrm{p}=0.129$, Fisher exact test)." 5 Despite that, the overall failure rate was still equivalent, as other components of the system failed, even when the proximal catheter performance improved. There were no Grade 3 catheter positions in the EM image guidance group; this did have a significant impact on shunt survival compared with Grades 1 and 2. These data were not analyzed independently for the pediatric patients included in the study. ${ }^{5}$

A recent paper by Levitt et al. ${ }^{9}$ also looked at the use of EM navigation versus standard shunt placement. The authors retrospectively analyzed 102 surgeries with frontal catheter placement in pediatric patients to identify the rates of subsequent shunt failure and catheter position- ing with the same grading as previously described. The authors found no significant difference in the incidence of proximal obstruction in the EM guidance group (25\%) compared with the standard technique group (22\%). There was significantly improved catheter positioning in the EM guidance group, although this had no impact on shunt survival. Patients in the EM guidance group were more likely to have small or difficult-to-navigate ventricular anatomy.

\section{Excluded Articles}

Seven articles were identified, reviewed, and ultimately excluded because of weak evidence, incomplete evidence, or irrelevance regarding the application of technical adjuvants. ${ }^{1,3,4,8,10-12}$ Lam and colleagues ${ }^{8}$ discussed a Seldinger technique for placing ventricular catheters over endoscopes, and included only a single case. A paper by Chernov et al. ${ }^{1}$ was excluded for a number of factors, including the fact that there were only 4 patients in one group (endoscopic third ventriculostomy [ETV]) and the inclusion range of 5-21 years included 5 patients who were 20 years of age or older. ${ }^{1}$ In a retrospective review, Shim and colleagues ${ }^{12}$ compared infants treated with ETV and shunts with infants treated with shunts alone. The authors found improved longevity of the shunt when combined with ETV. Gil et al. ${ }^{4}$ retrospectively evaluated ventricular catheter placement with a frameless optical navigation system, but their study included only 9 patients and was excluded for having a sample size smaller than 10. McMillen et al. ${ }^{10}$ used EM image guidance for a variety of conditions in children that included only 3 cases of hydrocephalus. Piatt and Garton's paper ${ }^{11}$ was excluded because it was an analysis of shunt failure and related infection symptoms and frequencies using data derived from two large multicenter studies without direct reference to the techniques being considered in this review. Finally, Farahmand and colleagues ${ }^{3}$ presented information on a large group of patients older than 16 years of age without separately reporting individuals between the ages of 16 and 19 years, who could have been included.

\section{Conclusions}

\section{Endoscopy}

ReCommendation: There is insufficient evidence to recommend using endoscopic guidance for routine ventricular catheter placement. STRENGTH OF RECOMMENDATION: Level I, high degree of clinical certainty.

\section{Ultrasound Guidance}

RECOMMENDATION: The routine use of ultrasound-assisted catheter placement is an option. STRENGTH OF RECOMMENDATION: Level III, unclear clinical certainty.

\section{Electromagnetic Image Guidance}

RECOMMENDATION: The routine use of computerassisted electromagnetic (EM) navigation is an option. StRENGTH OF RECOMMENDATION: Level III, unclear clinical certainty.

The availability and quality of evidence is variable 
throughout the literature for the application of technical adjuvants for catheter placement in the treatment of hydrocephalus by CSF shunting. The strongest body of evidence applies to the use of endoscopy in insertion of shunts. Based on this evidence, endoscopy cannot be recommended for routine use, as no benefit of its application could be identified in the available literature. Less evidence exists for ultrasound and EM image guidance, and therefore a conclusive recommendation cannot be made. Catheter position may be optimized with the application of these technologies, although they may not have an impact on overall outcome with regard to shunt longevity. Insufficient data exist for the use of technical adjuncts in patients with more challenging anatomy, or in the situation in which the ventricle is unable to be cannulated using standard anatomical techniques.

\section{Acknowledgments}

We acknowledge the American Association of Neurological Surgeons (AANS)/Congress of Neurological Surgeons (CNS) Joint Guidelines Committee for the members' reviews, comments, and suggestions; Laura Mitchell, Guidelines Project Manager for the CNS, for her contributions; Pamela Shaw, research librarian, for her assistance with the literature searches; Kevin Boyer for his assistance with data analysis; and Sue Ann Kawecki for her assistance with editing.

\section{Disclosure}

The systematic review and evidence-based guidelines were funded exclusively by the CNS and AANS Pediatric Section, which received no funding from outside commercial sources to support the development of this document.

Conflict(s) of Interest: None. All Task Force members declared any potential conflicts of interest prior to beginning work on this evidence review.

Author contributions to the study and manuscript preparation include the following. Conception and design: AANS/CNS Joint Section on Pediatrics. Acquisition of data: all authors. Analysis and interpretation of data: all authors. Drafting the article: Flannery. Critically revising the article: all authors. Reviewed submitted version of manuscript: all authors. Approved the final version of the manuscript on behalf of all authors: Flannery. Administrative/technical/material support: all authors. Study supervision: Flannery.

\section{References}

1. Chernov MF, Kamikawa S, Yamane F, Ishihara S, Hori T: Neurofiberscope-guided management of slit-ventricle syndrome due to shunt placement. J Neurosurg 102 (3 Suppl): 260-267, 2005

2. Clark S, Sangra M, Hayhurst C, Kandasamy J, Jenkinson M, Lee M, et al: The use of noninvasive electromagnetic neuronavigation for slit ventricle syndrome and complex hydro- cephalus in a pediatric population. Clinical article. J Neurosurg Pediatr 2:430-434, 2008

3. Farahmand D, Hilmarsson H, Högfeldt M, Tisell M: Perioperative risk factors for short term shunt revisions in adult hydrocephalus patients. J Neurol Neurosurg Psychiatry 80: 1248-1253, 2009

4. Gil Z, Siomin V, Beni-Adani L, Sira B, Constantini S: Ventricular catheter placement in children with hydrocephalus and small ventricles: the use of a frameless neuronavigation system. Childs Nerv Syst 18:26-29, 2002

5. Hayhurst C, Beems T, Jenkinson MD, Byrne P, Clark S, Kandasamy J, et al: Effect of electromagnetic-navigated shunt placement on failure rates: a prospective multicenter study. Clinical article. J Neurosurg 113:1273-1278, 2010

6. Kellnar S, Boehm R, Ring E: Ventriculoscopy-aided implantation of ventricular shunts in patients with hydrocephalus. J Pediatr Surg 30:1450-1451, 1995

7. Kestle JR, Drake JM, Cochrane DD, Milner R, Walker ML, Abbott R III, et al: Lack of benefit of endoscopic ventriculoperitoneal shunt insertion: a multicenter randomized trial. J Neurosurg 98:284-290, 2003

8. Lam CH, Horrigan M, Lovick DS: The Seldinger technique for insertion of difficult to place ventricular catheters. Pediatr Neurosurg 38:90-93, 2003

9. Levitt MR, O'Neill BR, Ishak GE, Khanna PC, Temkin NR, Ellenbogen RG, et al: Image-guided cerebrospinal fluid shunting in children: catheter accuracy and shunt survival. Clinical article. J Neurosurg Pediatr 10:112-117, 2012

10. McMillen JL, Vonau M, Wood MJ: Pinless frameless electromagnetic image-guided neuroendoscopy in children. Childs Nerv Syst 26:871-878, 2010

11. Piatt JH, Garton HJ: Clinical diagnosis of ventriculoperitoneal shunt failure among children with hydrocephalus. Pediatr Emerg Care 24:201-210, 2008

12. Shim KW, Kim DS, Choi JU: Simultaneous endoscopic third ventriculostomy and ventriculoperitoneal shunt for infantile hydrocephalus. Childs Nerv Syst 24:443-451, 2008

13. Villavicencio AT, Leveque JC, McGirt MJ, Hopkins JS, Fuchs HE, George TM: Comparison of revision rates following endoscopically versus nonendoscopically placed ventricular shunt catheters. Surg Neurol 59:375-380, 2003

14. Vries JK: Endoscopy as an adjunct to shunting for hydrocephalus. Surg Neurol 13:69-72, 1980

15. Whitehead WE, Jea A, Vachhrajani S, Kulkarni AV, Drake JM: Accurate placement of cerebrospinal fluid shunt ventricular catheters with real-time ultrasound guidance in older children without patent fontanelles. Technical note. J Neurosurg 107 (5 Suppl):406-410, 2007

Manuscript submitted June 25, 2014.

Accepted July 7, 2014.

Please include this information when citing this paper: DOI: 10.3171/2014.7.PEDS14323.

Address correspondence to: Ann Marie Flannery, M.D., Department of Neurological Surgery, Saint Louis University, 3565 Vista Ave., St. Louis, MO 63110. email: flanneam@slu.edu. 